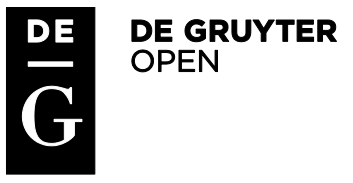

10.1515/topling-2016-0009

\title{
Bipolar items
}

\author{
Sumiyo Nishiguchi \\ Tokyo University of Science, Japan
}

\begin{abstract}
This article asserts that the Japanese wide-scope mo 'even' in simple sentences are bipolar items (BPIs) antilicensed or forbidden by negation and licensed in a non-monotonic (NM) environment. BPIs share the features of negative polarity items (NPIs) as well as positive polarity items (PPIs). The Dutch ooit 'ever', the Serbo-Croatian i-series 'and/even', and the Hungarian is-series 'and/even' are antilicensed by clausemate negation and licensed by extraclausal negation (van der Wouden, 1997; Progovac, 1994; Szabolcsi, 2002) or non-monotonic negative (and positive, for Serbo-Croatian) emotive predicates. Adding an NPI rescues BPIs in uncomfortable clausemate negation.
\end{abstract}

\section{Key words}

negation, non-monotonic, mo

\section{Bipolar Items}

1.1 NPIs and PPIs of different strength It is well known that negative polarity items (NPIs) are licensed in the scope of downward entailing (DE) environments (Fauconnier, 1975a; 1975b; Ladusaw, 1979). ${ }^{1}$ For example, in (1a), the NPI budge an inch is licensed by not, which is strongly negative, because the omission of not makes it ungrammatical (1b). On the contrary, in (2), positive polarity items (PPIs) such as already are anti-licensed and ungrammatical in a negative environment (Baker, 1970).

(1) a. John did not budge an inch. b.*John budged an inch.

\footnotetext{
1 For example, the NPI any is licensed in the scope of the downward entailing operator no fisherman. The statement no fisherman caught any fish semantically entails no fisherman caught any trout whose predicate is more restrictive, as in (ia), but the latter does not entail the former in (ib). No itself is also a downward entailing operator as shown in (ii).
}

(2) a. Simon has already arrived.

b. *Simon has not already arrived.

It has been observed that negative environments are classified into strong, medium and weak negativity (Zwarts, 1996; 1998). Anti-morphic (AM) determiners or noun phrases are strongly negative, antiadditive (AA) or anti-multiplicative (MP) expressions are medium negative, and monotone decreasing (MD) scope is weakly negative. Anti-morphism (AM) is De Morgan negation, which is a combination of anti-additivity (AA) and antimultiplicativity (MP).

Below I explain and exemplify AA, AM, MD, and MP cases in turn. For example, few is a monotonically, or constantly decreasing,

(i) a. No fisherman caught any fish. I= No fisherman caught any trout. b. No fisherman caught any trout. I $\neq$ No fisherman caught any fish.

(ii) a. No fisherman caught fish. I= No Sunday fisherman caught fish. b. No Sunday fisherman caught fish. $\mid \neq$ No fisherman caught fish. 
quantifier so that few dogs jump entails few poodles jump. In other words, few preserves the truth value for the subset of the set represented by the noun phrase in the scope. On the other hand, some is a monotonically increasing operator so that some days are cloudy entails some months are cloudy, but not vice versa. On the other hand, never is AA in that it never stops raining or snowing entails it never stops raining and it never stops snowing and vice versa. Not is AM, which is the combination of AA and MP so that Mary did not sing and dance is true if and only if Mary did not sing or Mary did not dance. Moreover, Mary did not sing or dance is equivalent to Mary did not sing and Mary did not dance.

(3) Monotone decreasingness (MD): Let $B$ be $a$ Boolean algebra. A quantifier $Q$ on $B$ is said to be monotone decreasing iff for each two elements $X$ and $Y$ of the algebra $B$ : if $X \in Q$ and $Y \subseteq X$, then $Y \in Q$.

(4) Anti-additivity (AA):

Let $B$ and $B *$ be two Boolean algebras. $A$ function $f$ from $B$ to $B *$ is said to be anti-additive iff for each two elements $X$ and $Y$ of the algebra $B$ : $f(X \cup Y)=f(X) \cap f(Y)$

(5) Anti-multiplicativity (MP):

Let $B$ and $B *$ be two Boolean algebras. $A$ function $f$ from $B$ to $B *$ is said to be antimultiplicative iff for each two elements $X$ and $Y$ of the algebra $B$ : $f(X \cap Y)=f(X) \cup f(Y)$

(Zwarts, 1996)

In addition, I define the NM scope, which is neither MD nor monotone increasing, in (6).

(6) Non-monotonicity (NM):

Let $B$ be a Boolean algebra. A quantifier $Q$ on $B$ is said to be nonmonotonic iff for each two elements $X$ and $Y$ of the algebra $B$ : if $X \in Q$ and $Y \subseteq X$, then $Y \notin Q$, and if $X \in Q$ and $X \subseteq Y$, then $\mathrm{Y} \notin \mathrm{Q}$.

Crucially, there are different levels of strength among NPIs and PPIs, namely, strong, medium and weak PIs. Weak NPIs such as any, ever and the Romanian indefinite vreun can be licensed in a DE context including monotone decreasing (MD), anti-additive (AA), anti-multiplicative (AP), anti-morphic (AM) and also in a nonmonotonic (NM) context (Nishiguchi 2003; 2004; Fălăuș, 2014). On the other hand, NPIs of medium strength are licensed only in $A A$ and $A M$ contexts and are ungrammatical in MD sentences. Strong NPIs are the most demanding of the three they live exclusively in AM environments.

\section{$1.2 \mathrm{BPIs}$}

With respect to BPIs, the Dutch ooit 'ever', the Serbo-Croatian i-series 'also/even' and the Hungarian is-series 'and/even' demonstrate NPI-hood by being licensed in medium and weak negative environments but demonstrate PPI-hood when antilicensed by strong clausemate negation (Szabolcsi p.c.; van der Wouden, 1997; Progovac, 1994; Szabolcsi, 2002). The crucial difference between weak NPIs and BPIs is that the latter dislikes strong negative contexts while the former likes them. Both, however, are licensed by weak and medium negation.

\subsubsection{Dutch Ooit}

The Dutch ooit 'ever' requires weak or medium negativity but is averse to antimorphic environments displayed in (7). Ooit requires the negative context as shown in (7a) and can be licensed in either the $A A$ or MD context in (7b) and (7c), respectively. However, the AM environment fails to license ooit as in (7d). Ooit in the embedded clause can be licensed by the negation in the matrix clause in (8).

$$
\begin{aligned}
& \text { (7)a. *Een van de kinderen } \\
& \text { One of the children } \\
& \text { gaat ooit bij oma op ezoek. } \\
& \text { goes ever with granny on visit. }
\end{aligned}
$$

b. Geen van de kinderen gaat ooit None of the children goes ever bij oma op bezoek. with granny on visit. 'None of the children ever visits granny.'

c. Weinig kinderen gaan ooit bij Few children go ever with oma op bezoek. granny on visit. 
'Few children ever visit granny.'

d. *Een van de kinderen gaat niet One of the children goes not ooit bij oma op bezoek. ever with granny on visit (AM; van der Wouden, 1994, p.57)

(8) Het is niet zo dat een van de It is not so that one of the kinderen ooit bij oma op children ever with granny on bezoek gaat.

visit goes

'It is not the case that one of the children ever visits granny.'

(van der Wouden, 1997, p.133)

Hoeksema (1998) discusses the current loss of the polarity sensitivity of ooit. According to his observations, ooit has become ambiguous between the NPI ooit and the non-sensitive ooit, which is also used as an existential temporal adverb nowadays. The latter appears in nonnegative contexts.

(9) a. Jan heft het ooit geweten. Jan has it once known 'Jan once knew it.'

b. Hier stond ooit een molen. Here stood once a mill 'A mill stood here, once.'

Jack Hoeksema also pointed out, at the Swarthmore Workshop on Negation and Polarity in 2006, that it is the Blocking Effect (Aronoff, 1976) that makes ooit ungrammatical in a strong negative context. The presence of another lexical item nooit blocks ooit from a strong negative context. However, van der Wouden (1997) argues that ooit also dislikes anti-morphic operators such as allesbehalve 'anything but' and allerminst 'not at all' in addition to niet.

(10) a. *Een van de kinderen gaat One of the children goes allesbehalve ooit anything.but ever bij oma op bezoek. with granny on visit

b. *Een van de kinderen gaat One of the children goes

\author{
allerminst ooit \\ not.at.all ever \\ bij oma op bezoek. \\ with granny on visit
}

The embedded clause under the AM matrix clause is AA (van der Wouden, 1997). In (11 a), Mary did not say can be interpreted to be the function $f$, whose argument contains disjunction. If this proposition is true, then the sentential conjunction of $f$ with each disjunct is true in the same model, and vice versa. However, $f$ with conjunction does not entail the sentential disjunction in (11b), which demonstrates AA property in the embedded clause.

(11) a. Mary did not say she went to Spain or Italy.

$<->$ Mary did not say she went to Spain and Mary did not say she went to Italy.

b. Mary did not say she went to Spain and Italy.

$-/>$ Mary did not say she went to Spain or Mary did not say she went to Italy.

\subsubsection{Hungarian and Serbo-Croatian}

Similarly, the Hungarian is-series 'also/even' and the Serbo-Croatian i-NPIs are ungrammatical with clausemate antimorphic negation. In the Hungarian data in (12a), is 'also/even' is ungrammatical in the AM context. In contrast, the MD and AA context in the embedded clause under negation license is as shown in (12b) and, (12c).

(12) a. *Nem értettél valamit
not understood-you something
is.
also/even
'You didn't understand
anything.'
(Hungarian, AM)
b. Kevés ember értett
few people understood
valamit is.
something also/even
'Few people understood
anything.'
(MD)


c. Nem hiszem, hogy valamit not think-I that something is értettél. also/even understood-you 'I don't think that you understood anything.' (Extra-clausal AM, Szabolcsi p.c.)

Likewise, the Serbo-Croatian $i$-'also/even' series require negation in the matrix clause as in (13a) but clausemate negation is not acceptable in (13b).

(13) a. Milan*(ne) tvrdi da Marija Milan not claims that Mary poznaje $\mathrm{i}(\mathrm{t}) \mathrm{ko}$-ga.

knows anyone-ACC

'Milan (does not) claims that Mary knows anyone.'

b. *Marija ne poznaje i(t)ko-ga. Mary not know anyone-ACC 'Mary does not know anyone.' (Progovac, 1994, p.42)

AM negation in the matrix clause creates the AA context in the embedded clause (van der Wouden, 1994, p.58).

(14) a. I did not say that Mary had arrived yet.

b. *Nobody said that Mary had arrived yet.

c. *Few people said that Mary had arrived yet.

Thus, BPIs in Dutch, Hungarian and SerboCroatian require an MD or AA context and are anti-licensed by a strongly positive context.

2. BPI Licensina in the non-monotonic scope of emotive predicates

Licensers of BPIs are not limited to the AA or MD contexts, such as extra-clausal negation and clausemate medium or weak negation. Negative emotives such as regret and doubt license BPIs in Dutch and Hungarian, as given in (15). The SerboCroatian data in (16) indicates that not only negative but also positive attitude predicates license BPIs in the embedded clause.

(15) a. Ik betreur (het) dat I regret it that ik dat ooit gedaen heb.

I that ever done have

'I regret what I have ever done.'

(Dutch, den Dikken p.c.)

b. Sajnálom, hogy valamit

regret-I that something-ACC

is adtam neki.

also/even gave-I to-him

'I regret that I gave him anything.'

(Hungarian, Szabolcsi p.c.)

(16) a. Sumnja-m da Milan voli

doubt-1SG that Milan loves

$\mathrm{i}(\mathrm{t}) \mathrm{ko}-\mathrm{ga} /{ }^{*} \mathrm{ni}(\mathrm{t}) \mathrm{ko}-\mathrm{ga}$.

anyone-ACC / no-one-ACC

'I doubt that Milan loves anyone.'

(Progovac, 1994, p.64)

b. Sretan sam da Milan

happy be.1sG that Milan

i(t)ko-ga voli.

anyone-ACc loves

'I am happy that Milan loves

anyone.'

The monotonicity of emotive predicates such as doubt, be happy, be surprised, and regret has posed a problem in FauconnierLadusaw's DE analysis of NPI licensing contexts, because these attitude predicates are not straightforward DE (Asher, 1987; Heim, 1992; von Fintel, 1999). For instance, I am happy that Mary bought a car does not imply I am happy that Mary bought a Honda, since the car Mary bought could be a Toyota. Similarly, the latter does not imply the former, for the speaker could be happy about the Honda and not necessarily glad that Mary spent money on a new car.

(17) a. I am happy that Mary bought a car.

$<-/->$ b. I am happy that Mary bought a Honda.

Without additional devices such as a weakened DE (Asher, 1987) or Strawson DEness (von Fintel, 1999), attitude predicates are non-monotonic. Both the weakened DE and the Strawson Entailment add additional assumptions such that the complement clause of the conclusion is also believed. 
(18) I am happy that Mary bought a car. Mary bought a Honda.

$\therefore$ I am happy that Mary bought a Honda

Thus far, we have seen that BPI licensing ranges from $A A$ and $M D$ to the NM context. BPIs dislike clausemate negation which is $\mathrm{AM}$, and demand weak or medium negative contexts, which are MD and AA, respectively. Extra-clausal negation and superordinate emotive predicates can also license BPIs in their AA or NM scope. While Dutch and Hungarian BPIs are only licensed by negative emotives, Serbo-Croatian BPIs can be licensed by positive emotives.

\section{Wide-scope even and non monotonicity}

The Japanese wide-scope mo 'also/even' behaves as BPIs when anti-licensed by clausemate negation or licensed in monotone decreasing contexts. Widescope even sentences are simple sentences embedded under implicit emotives such as be sorry, regret, or be happy.

\subsection{Wide-scope sentence focus mo 'even' in Japanese}

The Japanese additive mo 'also/even' typically scopes over the noun phrase and requires an explicit antecedent, as does the English additive also/too; for example, John is the antecedent of Mary in John came, and Mary came too (see (19) for the same example in Japanese). The meaning of 'even' appears when mo 'also/even' attaches to a noun phrase that refers to a scalar endpoint; for instance, in (20), John is the least likely person to come.

$$
\begin{aligned}
& \text { (19) John-ga ki-te, Mary-mo } \\
& \text { John-NOM come-and Mary-also } \\
& \text { ki-ta. } \\
& \text { come-PAST } \\
& \text { 'John came and so did Mary.' }
\end{aligned}
$$

(20) a. (Surprisingly,) JOHN-mo ki-ta. John-even come-PAST 'Even John came.'

\footnotetext{
2 Japanese grammarians have considered mo polysemous (Sadanobu 1997).
}
b. *JOHN-mo ko-nakat-ta.
(AM)
John-even come-NEG-PAST
'Even John did not come.'

When mo attaches to $w h$-words, it forms any-type strong NPIs (Kato, 1985; Kato, 2000; Nam, 1994) or negative concord items (Watanabe, 2004). ${ }^{2}$
(21) Dare-mo ko-nakat-ta. (AM) who-also come-NEG-PAST
'Nobody came.'

(22) a. *Dare-mo torihiki-o kyozetsusuru.

who-also deal-ACC

refuse

'Anyone refuses a deal.'

b. Dare-mo torihiki-o

kyozetsushi-nai.

(AM)

who-also deal-ACC

refuse-NEG

'Nobody refuses to raise hand.'

(23) a. *Seizei 5-nin-ga ani-mo

iu.

at most 5-CL-NOM what-also

say

'At most five people say

anything.'

b. ?Seizei 5-nin-ga nani-mo

iwa-nai.

at most 5-CL-NOM what-also

say-NEG

'At most five people say

nothing.'

When mo 'even' attaches to a scalar endpoint, NP-mo is a minimizer weak NPI.

(24) a. Hito-ri-mo ko-nakat-ta. (AM)

1-CL-even come-NEG-PAST

'Nobody came.'

b. \#Hitori-mo ki-ta.

1-CL-even come-PAST

'Even one person came.' 
(25) a. Sukoshi-mo nai. little-even NEG

'There is nothing.'

b. "Sukoshi-mo aru. little-even exist 'There is little.'

(26) a. Menkai-wa hito-ri-mo kyozetsusuru. visit-TOP 1-CL-even refuse

'Any visitors are refused.'

b. Denwa ip-pon-mo

kyozetsusuru.

Phone 1-CL-even

refuse

'(He) refuses even a single phone call.'

There is a wide-scope mo 'even' given in (27b) and (28). Numata (2000) claims that this $m o$ 'also/even' takes a wide scope over a proposition and triggers presupposed implicit events. This mo can appear unexpectedly discourse-initially, and does not require a discourse antecedent.

(27) a. Shikuramen-mo karete-ki-ta. (narrow scope mo) cyclamen-even wither-ASP-PAST 'Even cyclamens come to wither.'

b. Shikuramen-mo karete-ki-ta.

Mo haru-da.

cyclamen-even wither-ASP-PAST already spring-DECL

'Even cyclamens have withered. Spring has already come.' (wide scope mo)

(28) a. Yo-mo fukete-ki-ta. night-even late-become-PAST Mo neru-toshi-yo. already sleep-comp do-will 'It has become late (at night). It's time to go to bed.'

b. Ko-no saifu-mo this-GEN wallet-even

3 I would like to thank the reviewers of Dgfs 37 AG 9: Varieties of Positive Polarity Items for making me aware of this. furuku-nat-ta.

old-become-PAST

'This wallet has become old.'

c. Mari-mo kashiko-i.

Mari-even smart-be

'Mary is indeed smart.'

d. Soto-mo hiete-ki-ta.

outside-even cold-ASP-PAST

'It has become cold outside.'

e. Tabi-mo owari-ni

trip-even end-to

chikazuite-ki-ta.

approach-ASP-PAST

'The trip is coming to an end.'

f. Omae-mo aho-ya-na.

you-even silly-DECL-EXC

'You are indeed silly.'

I consider this mo to be the wide-scope even, ${ }^{3}$ while this mo has been considered by others to mean also (Yamamori, 2014). (27a) and (27b) can be represented as in (29).

(29) a. Even [cyclamens] $\mathrm{F}$ have withered. (Narrow scope even)

b. The cyclamens have even withered. (Presentational focus wide scope even) Even [the cyclamens have withered $]_{\mathrm{F}}$

If we consider this mo to be a wide-scope even, Rooth's (1987) focus semantics derives focus alternatives from $\mathrm{mo}^{-}$ sentences. Rooth (1987) discussed the wide-scope or sentential scope even. Even in English associates with a phrase $\alpha$ if and only if even c-commands $\alpha$ (Rooth, 1987, p.92; Jackendoff, 1972, p.249). While mo does not require a c-commanding relation, Rooth's ILF style translation in (30) yields conventional implicature that there is another unlikely proposition in the context set, for example, the weather has become even warmer, or tulips have even started to bloom. 
(30) $\left.F_{\text {even,t }}(\text { withered'([cyclamens }]_{\mathrm{F}}\right)=$ $\exists p[C(p) \& \vee P \& p \neq$

'withered'([cyclamens] $]_{F} \&$ unlikely'(p)) \& withered'([cyclamens] $\left.]_{\mathrm{F}}\right)$

On the other hand, the scalar implicature for both the narrow- and wide-scope mo can be provided, following the work of Karttunen and Peters (1979).

(31) Focus of DP focus narrow scope even: [cyclamens]

(32) Focus of wide-scope even: [cyclamens have withered] (sentence-focus)

(33) Scope of wide-scope even: $x$ has withered

(34) Existential implicature for narrowscope even: there are other $x$ under consideration besides cyclamens such that $x$ has withered.

(35) Scalar implicature for narrow-scope even: for all $\mathrm{x}$ under consideration besides cyclamens, the likelihood that $x$ has withered is greater than the likelihood that cyclamens have withered.

(36) Existential implicature for widescope even: there are other $\mathrm{p}$ under consideration besides $p$.

(37) Scalar implicature for wide-scope even: for all $\mathrm{p}$ under consideration besides cyclamens have withered, the likelihood for $p$ is greater than the likelihood that cyclamens have withered.

(38) The scalar implicature of the widescope mo sentence is that cyclamens have withered is most unlikely compared to other

4 As mentioned earlier, the embedded clause under $A M$ negation in the matrix clause is $A A$, and not antimultiplicative or AM, as pointed out by van der Wouden.

(i) It is not right that drivers or bikers turn left here. occurrences such as warmer weather.

Both the focus alternatives in Rooth (1987) and the scalar implicature of Karttunen and Peters (1979) work for the wide-scope mo. This mo has sentence-focus structures in the sense of Lambrecht (1994). As an answer to the question what happened, the entire proposition my car broke down is new information and is therefore focused on.

(39) a. What happened? My CAR broke down.

b. Presupposition: -

c. Assertion: 'speaker's car broke down'

d. Focus domain: 'speaker's car broke down'

e. Focus: $\mathrm{S}$ (Lambrecht, 1994, p.233)

The discourse-initial mo is a BPI that shows PPI-hood when anti-licensed by clausemate negation, as in (40a), (41a), and (42)-(44). Moreover, the wide-scope $m o$ is licensed in extra-clausal strong negation that makes the embedded clause AA in (40b) and (41b); MD numeral, at most $n$ (45); AA environment in (46); and NM emotives as in (47).

$$
\begin{aligned}
& \text { AM a. *Yo-mo sue-ja-nai. } \\
& \text { world-even end-be-NEG } \\
& \text { 'This is not the end of the } \\
& \text { world.' }
\end{aligned}
$$
AA b. Yo-mo sue-da-to- world-even, end-be-CoMp- iu- koto-wa-nai. say-fact-TOP-NEG 'It is not true that this is the end of the world.' 4
(41) a. *Tabi-mo owari-ni trip-even end-DAT chikazuite-ko-nai. approach-ASP-NEG

$->\quad$ It is not right that drivers turn left here and it is not right that bikers turn left here.

(ii) It is not right that drivers and bikers turn left here

$-/->\quad$ It is not right that drivers turn left here or it is not right that drivers turn left here. 
'The trip is not drawing to an end.'

b. Tabi-mo owari-ni trip-even end-DAT chikazuite-ki-ta-wake-demo-nai. approach-ASP-PAST-reason-be-NEG 'It is not that the trip is drawing to an end.'

(42) *Shikuramen-mo cyclamen-even karete-ko-nakat-ta. wither-ASP-NEG-PAST

(43) *Mari-mo kashikoku-nai. Mari-even smart-NEG

(44) *Kono saifu-mo this wallet-even furuku-nar-anat-ta. old-become- NEG-PAST

(45) MD Seizei 5-nin-no gakusei-mo at most 5-CL-GEN student-even ganbat-ta.

do.one's.best-PAST

'At most five students did their best.' 5

(46) AA Moshi tabi-mo owari-ni

5 Seizei $n$ 'at most $\mathrm{n}$ ' in Japanese is MD as pointed out by Yoshimura (1999, p.130).

6 Moshi...nara, the conditional if-clause in Japanese is AA (Yoshimura, p.1999).

(i) Moshi ame-ka yuki-ga

futta-nara asu-wa

yasumi-da.

if rain-or snow-NOM drop-then

tomorrow-TOP off-DECL

'If it rains or snows, we will be off tomorrow.'

->Moshi ame-ga futta-nara asu-wa yasumi-da-shi, moshi yuki-ga futtemo asu-wa yasumi-da.

'If it rains, we will be off tomorrow and if it snows, we will be off too'

(ii) Moshi ame-to yuki-ga futta-nara asu-wa yasumi-da.

if rain-and snow-NOM drop-then tomorrow-TOP off-DECL

'If it rains and snows, we will be off tomorrow.'

-/->Moshi ame-ga furu-nara asu-wa yasumi-ka, moshi yuki-ga futtaraasu-wa yasumi-ka-da.
If trip-even end-GOAL

chikazuita-nara ii-noni.

near-then good-but

"I wish the trip was coming to an end.'6

(47) NM a. Yo-mo fukete-ki-te

night-even late-become-PAST.and

zannen-da.

regretful-be

'I am sorry that it's late (at night).'

b. Shikuramen-mo

cyclamen-even

karete-ki-te kanashii.

wither-come-PAST.and sad

'I am sad the cyclamens have withered.'

Even though the typical mo-sentences of this sort are simple declarative sentences, the speaker's sentimental emotions, either negative or positive, are indispensable. As such, emotives create NM scope, and mosentences are licensed in a covertly NM environment.

(48) a. (Zannenna-koto-ni) yo-mo regretful-fact-GOAL night-even fukete-ki-ta. ${ }^{7}$

'If it rains, we will be off tomorrow or if it snows, we will be off tomorrow.'
7 The scope of zannenna-koto-ni 'regretably/unfortunately' is NM:

(i) Zannenna-koto-ni ame-to yuki-ga futteki-ta.
regret-fact-DAT
rain-and

snow-NOM

'Regrettably it started to rain and snow.' $<-/->$ Zannenna-koto-ni amega fut-teki-ta-ka, yuki-gafutteki-ta.

regret-fact-DAT rain-NOM fall-ASP-PAST-or snow-NOM fallASP-PAST

'Regrettably it started to rain or it started to snow.'

(ii) Zannenna-koto-ni ame-ka yuki-ga futteki-ta.

$<-/->\quad$ Zannenna-koto-ni ame-ga

fut-teki-te, yuki-mo

regret-fact-DAT rain-NOM fall-ASP-PASTand snow-also

fut-teki-ta.

fall-ASP-PAST 
late-become-PAST

'(I am sorry that) it has become late (at night).'

b. (Shimijimi-to) Ko-no heartily-COMP this-GEN saifu-mo furuku-nat-ta. wallet-even old-become PAST '(Heartily) This wallet has become old.'

(49) (Ureshii-koto-ni) haru(happy-fact-GOAL) spring-even motakenawa-ni nari-mashi-ta. ${ }^{8}$ peak-GOAL become-HON-PAST '(I'm glad that) spring has reached its peak.'

(50) Scalar implicature: for all situations $s$ under consideration besides the one that spring has reached its peak, the likelihood for $s$ greater than the likelihood that spring reached its peak. (cf., Karttunen and Peters, 1979)

Therefore, the BPI licensing environments in Japanese are: (i) downward entailing scope (MD), (ii) extra-clausal antimorphic negation (AA), (iii) extra-clausal nonmonotonic emotives (NM), and (iv) covert superordinate emotives (NM). Covert superordinate emotives are peculiar to Japanese, Korean and Chinese BPIs.

4. Modal-like elements or the NPI rescues BPIs with negation

The insertion of an NPI rescues BPIs in otherwise uncomfortable AM environments, as in (51). ${ }^{9}$ Moreover, (52) indicates that the presence of a modal-like element also rescues otherwise uncomfortable BPIs under negation. 10

(51) Ko-no saifu-mo \#(zenzen/amari) tsukawa-nakat-ta.

this-GEN wallet-even at all/much

use-NEG-PAST

'I have not used this wallet at

'Regrettably it started to rain and it started to snow as well.'

8 The body of this sentence is taken from Numata (2000), even though Numata does not discuss speaker attitudes towards the all/much.'

(52) a. Kare-mo kekkon-seikatsu-mo he-even marriage-life-also umaku ika-nakat-ta-ne. well go-NEG-PAST-PAR 'His married life did not go well, did it?'

b. Kono hon-mo yoku this book-even well wakara-nakat-ta-ne. can.understand-NEG-PAST-PAR 'This book was also hard to understand, wasn't it?'

c. Ano baito-mo tsukae-nakat-ta. that part-time-worker-even can.use-NEG-PAST 'That part-time worker was not usable, either.'

Example (51) indicates that the NPI zenzen/amari improves the grammaticality of the sentence with the BPI anti-licensed by $A M$ negation. In (52), the presence of non-monotonic modal-like elements licenses the illegitimate clausemate BPI.

\section{BPI Licensing Contexts}

In view of the previous data, BPI licensers are either MD, AA, extra-clausal AM negation, or NM explicit/implicit emotives; therefore, BPI licensing contexts can be summarized as follows:

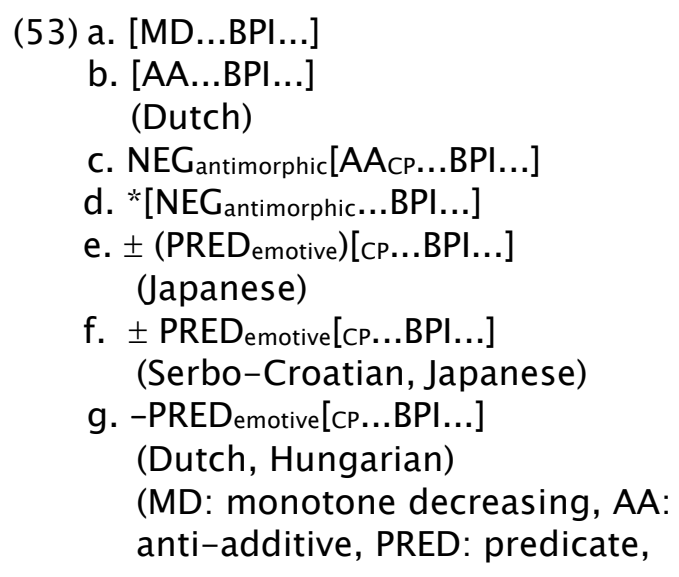

propositions.

9 I thank Heejeong Ko for bringing this to my attention.

10 Thanks to Hiroshi Mito for suggesting example (52). 


$$
\begin{aligned}
& \text { +: positive, -: negative, ( ): } \\
& \text { implicit) }
\end{aligned}
$$

As shown in $(53 a, b)$, BPIs can be licensed in MD or AA context, or by AM negation in the matrix clause which makes the embedded clause AA, as in (53c). BPIs dislike the AM environment as in (53d) while NM positive or negative emotives license them in the embedded clause, when they are implicit as in (53e) or explicit in (53f). Some languages allow only negative emotives to be the BPI licensers as in $(53 \mathrm{~g})$.

\section{Conclusion}

This article discussed BPIs - which share the features of both NPIs and PPIs. As NPIs, BPIs are licensed in $A A$ and $M D$ contexts. As PPIs, BPIs are ungrammatical with clausemate negation. BPIs are licensed by extra-clausal explicit or implicit NM factive emotives as well as superordinate negation. Adding an NPI rescues BPIs in clausemate negation.

The presence of such BPIs makes us wonder whether there exist more BPIs in other languages parallel to the NPIs and PPIs widely observed cross-linguistically. Moreover, BPIs ambiguate the borderline between negative and positive polarity, which brings into question the coherent distribution of polarity items.

\section{References}

ARONOFF, M., 1976. Word formation in generative grammar. Cambridge, MA: MIT Press.

ASHER, N., 1987. A typology for attitude verbs and their anaphoric properties. Linguistics and Philosophy, vol.10, pp.125-197.

BAKER, C. L.,1970. Double negatives. Linguistic Inquiry, vol.1, pp.169-186.

FÂLÂUS, A., 2014. (Partially) Free choice of alternatives. Linguistics and Philosophy, vol.37, pp.121-173.

FAUCONNIER, G., 1975a. Polarity and the scale principle. In: CLS 11, pp. 188-199.

FAUCONNIER, G., 1975b. Pragmatic scales and logical structure. Linguistic Inquiry, vol.6, pp. 353-375.

von FINTEL, K., 1999. NPI licensing, Strawson entailment, and context dependency. Journal of Semantics, vol.16, pp.97-148.

HEIM, I., 1992. Presupposition projection and the semantics of attitude verbs. Journal of Semantics, vol.9, pp.183-221.

HOEKSEMA, J., 1996. In days, weeks, months, years, ages: A class of negative polarity items. Ms.

HOEKSEMA, J., 1998. On the (non)loss of polarity sensitivity. In: Historical Linguistics 1995, vol. 2: Germanic Linguistics. Amsterdam: John Benjamins, pp.101-114.

JACKENDOFF, R. S., 1972. Semantic interpretation in generative grammar. Cambridge: MIT Press.

KARTTUNEN, L. and PETERS, S., 1979. Conventional implicature. In: Syntax and Semantics, vol. 11. Presupposition. Academic Press.

KATO, Y., 1985. Negative sentences in Japanese. Sophia Linguistica, vol.14, pp.1-229.

KATO, Y., 2000. Interpretive asymmetries of negation. In: Negation and Polarity: Syntactic and Semantic Perspectives. Oxford: Oxford University Press, pp. 62-87.

LADUSAW, W. A., 1979. Polarity sensitivity as inherent scope relations. Ph.D. diss., University of Texas, Austin.

LAMBRECHT, K., 1994. Information structure and sentence form. Cambridge: Cambridge University Press.

NAM, S., 1994. Another type of negative polarity item. In: Dynamics, polarity, and quantification. Stanford: CSLI, pp.3-15.

NISHIGUCHI, S. 2003. Non-monotonic Negativity. In D. H. Ji et al. eds., Proceedings of PACLIC 17. Sentosa, Singapore: COLIPS, pp. 204-215.

NISHIGUCHI, S. 2004. Five Types of Affective Contexts: Nonmonotonic NPI Licensers. In N. Adams et al. eds., CLS 40-1. Chicago: The Chicago Linguistic Society, pp. 249-264.

NUMATA, Y., 2000. Toritate [focus]. In: S. Kinsui, M. Kudo and Y. Numata, eds. Toki, hitei to toritate. Tokyo: Iwanami, pp.151-216.

PROGOVAC, L., 1994. Negative and positive polarity: $\boldsymbol{A}$ binding approach. Cambridge: Cambridge University Press. 
ROOTH, M., 1985. Association with Focus. PhD Thesis, University of Massachusetts, Amherst, GLSA Publications.

SADANOBU, T., 1997. Shinteki prosesu kara mita toritateshi te, demo, ni-hongo no shudai to toritate. Tokyo: Kuroshio, pp.227-260.

SZABOLCSI, A., 2002. Hungarian disjunctions and positive polarity. In: Approaches to Hungarian, vol. 8, Budapest: Akadémiai Kiadó.

van der WOUDEN, T., 1994. Negative contexts. PhD thesis, University of Groningen.

van der WOUDEN, T., 1997. Negative contexts: Collocation, polarity and multiple negation. London: Routledge.

WATANABE, A., 2004. The genesis of negative concord: Syntax and morphology of negative doubling. Linguistic Inquiry, vol.35, pp.559-612.

YAMAMORI, Y., 2015. Perspective shift-to kongo waho [Perspective Shift and Blended Speech in Japanese]. Tokyo: Hitsuji Shobo.

YOSHIMURA, A., 1999. Hitei kyokusei gensho [Negative Polarity Phenomena]. Tokyo: Eihosha. ZWARTS, F., 1996. A hierarchy of negative expressions. In: H. Wansing, ed. Negation: A notion in focus. Berlin: Walter de Gruyter, pp.169-194.

ZWARTS, F., 1998. Three types of polarity. In: F. Hamm and E. Hinrichs, eds. Plurality and quantification. Dordrecht: Kluwer Academic, pp.177-238.

\author{
Authors' address and contact details \\ Sumiyo Nishiguchi, PhD. \\ Department of Science \\ Tokyo University of Science \\ 1-3 Kagurazaka, Shinjuku \\ Tokyo \\ Japan \\ E-mail: nishiguchi@rs.tus.ac.jp
}

